\title{
Effect of Long-chain Fatty Acids on Some Trypanosomatid Flagellates
}

\author{
By L. V. CUNNINGHAM, B. H. KAZAN AND S. S. KUWAHARA* \\ Department of Microbiology and Department of Chemistry, California State College, \\ Long Beach, California 9080 , U.S.A.
}

(Accepted for publication 4 December 197I)

\begin{abstract}
SUMMARY
A long-chain fatty-acid fraction obtained from the marine alga, Ulva lactuca, as well as decanoic, dodecanoic and hexadecanoic acids at levels of $250 \mu \mathrm{g} / \mathrm{ml}$ induced lysis of various Trypanosomatidae. However, octanoic and cis-9-octadecenoic acids at higher concentrations had no effect. Decanoic, dodecanoic and hexadecanoic acids at levels below $100 \mu \mathrm{g} / \mathrm{ml}$ inhibited motility of the promastigotes of Leishmania donovani and L. tropica, and the epimastigotes and trypomastigotes of Trypanosoma cruzi. Crithidia fasciculata was relatively resistant to fatty acids and was not affected by decanoic acid at this level.

The lysis induced by the marine algal fatty acids and by decanoic and dodecanoic acids was preceded by the formation of rounded forms of the haemoflagellates which indicated the loss of membrane structure.
\end{abstract}

\section{INTRODUCTION}

Preliminary observations indicated the presence of trypanocidal compounds in a marine alga. Studies on a methanol extract of dried fronds from Ulva lactuca showed that the activity resided in a fatty-acid fraction obtained after silicic-acid chromatography of the crude extracts. This result was interesting in light of the studies of Boné \& Parent (1963), who found that $25 \mu \mathrm{g}$ octadecanoic acid $/ \mathrm{ml}$ or $100 \mu \mathrm{g}$ docosanoic acid $/ \mathrm{ml}$ would act as growth factors for Trypanosoma cruzi, our test organism. At the same time, these workers found that cis, cis-9, 12-octadecadienoic and eicosanoic acids had no effect while dodecanoic, tetradecanoic, hexadecanoic, cis-9-hexadecanoic, cis, cis, cis-9,12,15-octadecatrienoic, cis-9octadecanoic, and all cis-5,8, I I, I4-eicosatetraenoic acids had an adverse effect upon the organism. The nature of this 'adverse effect' was not noted, and the results observed in this study were rather unusual in that an organism would not be expected to have such a specific response to such closely related fatty acids. Also, Balis (I966) showed that low concentrations ( 0.10 to $0.01 \mathrm{mg} / \mathrm{ml}$ ) of C-I 2 to C-I 8 saturated fatty acids and unsaturated C-I 8 fatty acids prevented the survival in vitro of Trypanosoma evansi while C-4 to C-6 saturated fatty acids had no effect. Dodecanoic and cis, cis-9,12-octadecadienoic acids were the most toxic, causing lysis of this organism.

While it is known that fatty acids of various types are toxic to many micro-organisms (Nieman, 1954), the lack of information on the effects of long-chain fatty acids upon the various trypanosomes led us to extend our studies to a comparison of the effects of known long-chain fatty acids on members of the Trypanosomatidae.

* To whom inquiries concerning this paper should be addressed at the Department of Developmental and Cell Biology, University of California, Irvine, California 92664, U.S.A. 


\section{METHODS}

Four species of Trypanosomatidae were used. Crithidia fasciculata (ATCC I I745), Leishmania donovani and L. tropica were acquired from Mrs Eleanor Tobie, National Institutes of Health, Bethesda, Maryland, U.S.A., and Trypanosoma cruzi Md-R was obtained from Col. Bryce Walton, United States Army Medical Corps, Canal Zone, Panama.

The choanomastigote stage of Crithidia fasciculata, the epimastigote stage of Trypanosoma cruzi, and the promastigote states of Leishmania donovani and L. tropica were maintained in a modified NNN medium at 25 to $27^{\circ}$ and transferred every 15 days. The modified NNN medium was composed of a basal layer of $3.7 \%(\mathrm{w} / \mathrm{v})$ brain-heart infusion agar, $\mathrm{I} \%(\mathrm{w} / \mathrm{v})$ glucose, $\mathrm{I} \%(\mathrm{w} / \mathrm{v})$ agar, and an overlay of $\mathrm{I} \%(\mathrm{v} / \mathrm{v})$ of a mixture of penicillin-C (10000 units $/ \mathrm{ml}$ ) and potassium dihydrostreptomycin $(10 \mathrm{mg} / \mathrm{ml}$ ) in phosphate-buffered saline (PBS). (PBS was an aqueous solution containing $10.64 \mathrm{~g} \mathrm{~K}_{2} \mathrm{HPO}_{4} \cdot 3 \mathrm{H}_{2} \mathrm{O}, 2 \cdot 72 \mathrm{~g} \mathrm{KH}_{2} \mathrm{PO}_{4}$ and $8.5 \mathrm{~g} \mathrm{NaCl}$ per $1000 \mathrm{ml}$. The final $\mathrm{pH}$ ranged from $7 \cdot 0$ to $7 \cdot 2$.) Seven-day-old cultures were used for all experiments. The trypomastigote stage of Trypanosoma cruzi was propagated on green-monkey kidney tissue in Eagle's Basal Medium (BME) for five days.

Ulva lactuca was collected from Los Alamitos Bay, California, U.S.A., and rinsed five times in tap water and twice in distilled water to remove extraneous material before blotting on paper towels, placing in porcelain trays and drying at room temperature $\left(25\right.$ to $\left.27^{\circ}\right)$ for 24 to $48 \mathrm{~h}$.

Preliminary studies involved extraction of the alga with redistilled methanol. In later studies the dried algal material was extracted by saponification with $0.4 \mathrm{~N}-\mathrm{NaOH}$ in $70 \%$ ethanol.

Chromatography of the saponified algal extract. Silicic acid (CC-4, Mallinckrodt, St Louis, Missouri, U.S.A.) (200 to 300 mesh) was sized and poured as a slurry in chloroform into a glass column $(3 \times 56 \mathrm{~cm})$ and washed with $2.5 \%(\mathrm{v} / \mathrm{v})$ diethyl ether in hexane. The dried algal material was extracted with $0.4 \mathrm{~N}-\mathrm{NaOH}$ in $70 \%$ ethanol by boiling the mixture for $5 \mathrm{~min}$. The initial extract was acidified with concentrated $\mathrm{HCl}$, diluted with an equal volume of water, and extracted with ether. The ether extract was dried on a rotary evaporator and taken up in $2.5 \%$ diethyl ether in hexane. The crude extract $(9100 \mathrm{ml}$ in $2.5 \%$ diethyl ether in hexane) was then added to the column and the fatty acids were separated from other lipids by eluting the column with five column volumes of different solvent mixtures, beginning with $2.5 \%(\mathrm{v} / \mathrm{v})$ diethyl ether in hexane and ending with $100 \%$ diethyl ether (Barron \& Hanahan, 1958). A sample of each fraction was dried, reconstituted in PBS and tested for antitrypanosomal activity. An infrared spectrum of the presumed fatty-acid fraction from this column confirmed the presence of fatty acids.

Fatty-acid solutions. One gram each of octanoic, decanoic, dodecanoic, hexadecanoic, and cis-9-octadecanoic acids were placed separately in $100 \mathrm{ml}$ prescription bottles containing $50 \mathrm{ml}$ of PBS. The bottles were thoroughly shaken and placed in a water bath at $37^{\circ}$ for $24 \mathrm{~h}$ to obtain a saturated solution. The dispersions were then adjusted to $\mathrm{pH} 7{ }^{\circ} \mathrm{O}$ with $0 . \mathrm{I} \mathrm{N}-\mathrm{NaOH}$ and filtered through Whatman no. I paper to remove particles.

One gram of a dried methanol extract from algal fronds and I $\mathbf{g}$ of the dried fatty-acid fraction from the silicic acid column (eluted with $10 \%(\mathrm{v} / \mathrm{v})$ diethyl ether in hexane) were mixed with $30 \mathrm{ml}$ of PBS in separate $100 \mathrm{ml}$ prescription bottles and treated in the same way as the pure fatty acids. The concentration of these fatty-acid preparations (methanol extract, column fraction and pure fatty acids) in PBS was determined gravimetrically by means of a Cahn Electro-balance.

Trypanosome-inhibition studies. Activities of the known fatty acids and the algal extracts 


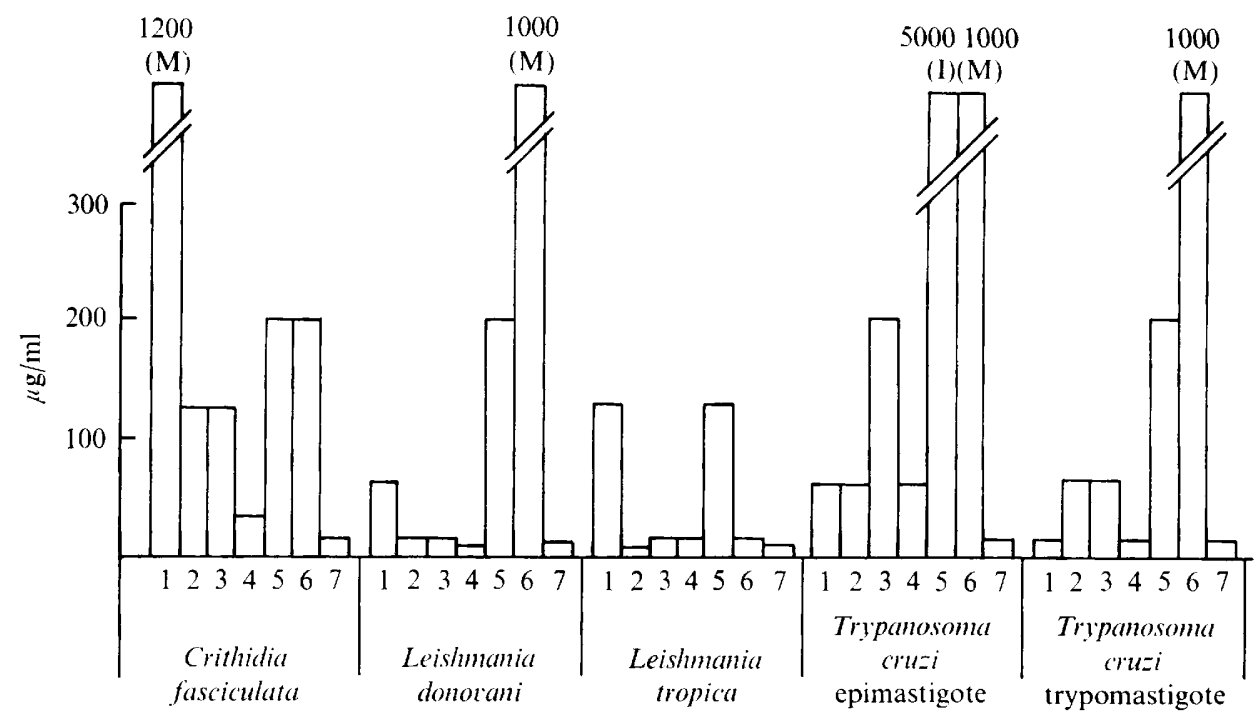

Fig. 1. Minimum concentrations of compounds which inhibited motility of trypanosomes. Assay conditions are described in the methods section. 1 , Crude methanolic algal extract; 2 , algal fatty acid fraction from silicic acid column; 3, decanoic acid; 4, dodecanoic acid ; 5, octanoic acid; 6, cis-9octadecanoic acid; 7, hexadecanoic acid; I, inhibition of motility produced at this concentration; $\mathrm{M}$, organism still motile at this level.

(total methanol extract and chromatographed fatty acids) in PBS were tested against the following: the epimastigote and trypomastigote stages of Trypanosoma cruzi, the choanomastigote stage of Crithidia faciculata, and the promastigote stages of Leishmania donovani and $L$. tropica. The solutions to be tested were autoclaved at $12 \mathrm{I}^{\circ}$ for $\mathrm{I} 5 \mathrm{~min}$ cooled to $25^{\circ}$ and diluted with sterile PBS.

The NNN overlay and BME (tissue-culture supporting medium) containing parasites were centrifuged at $1000 \mathrm{~g}$ for $10 \mathrm{~min}$. The supernatant was carefully decanted and the parasites were resuspended in sterile PBS. A $0.5 \mathrm{ml}$ suspension containing $\mathrm{I} \times 10^{7}$ parasites was added to each tube. The parasite concentration was determined with a haemocytometer. Control tubes contained only PBS and parasites.

Wet-mount observations were made at I, 3, 6, I 8 and $24 \mathrm{~h}$. The minimum concentration of the compounds which inhibited the motility of the parasites after $24 \mathrm{~h}$ of incubation was determined in most instances. In two the final readings were made at $6 \mathrm{~h}$ as the control tubes showed no activity at $\mathrm{I} 8 \mathrm{~h}$.

\section{RESULTS}

Preliminary studies revealed that the methanol extract of Ulva lactuca dissolved in PBS inhibited the motility of Trypanosoma cruzi. Thin-layer chromatography on Silica Gel G showed that the active substance was a fatty acid and not a sterol. The fatty-acid fraction from the silicic acid column possessed antitrypanosomal activity.

Gas-liquid chromatography of methyl esters revealed that the fatty-acid fraction from the silicic acid column contained octanoic, nonanoic, decanoic, undecanoic and dodecanoic acids and many unidentified fatty acids.

The results showed that the algal extracts and the known fatty acids were inhibitory at low concentrations. For the promastigote stage of Leishmania donovani and the trypomastigote 

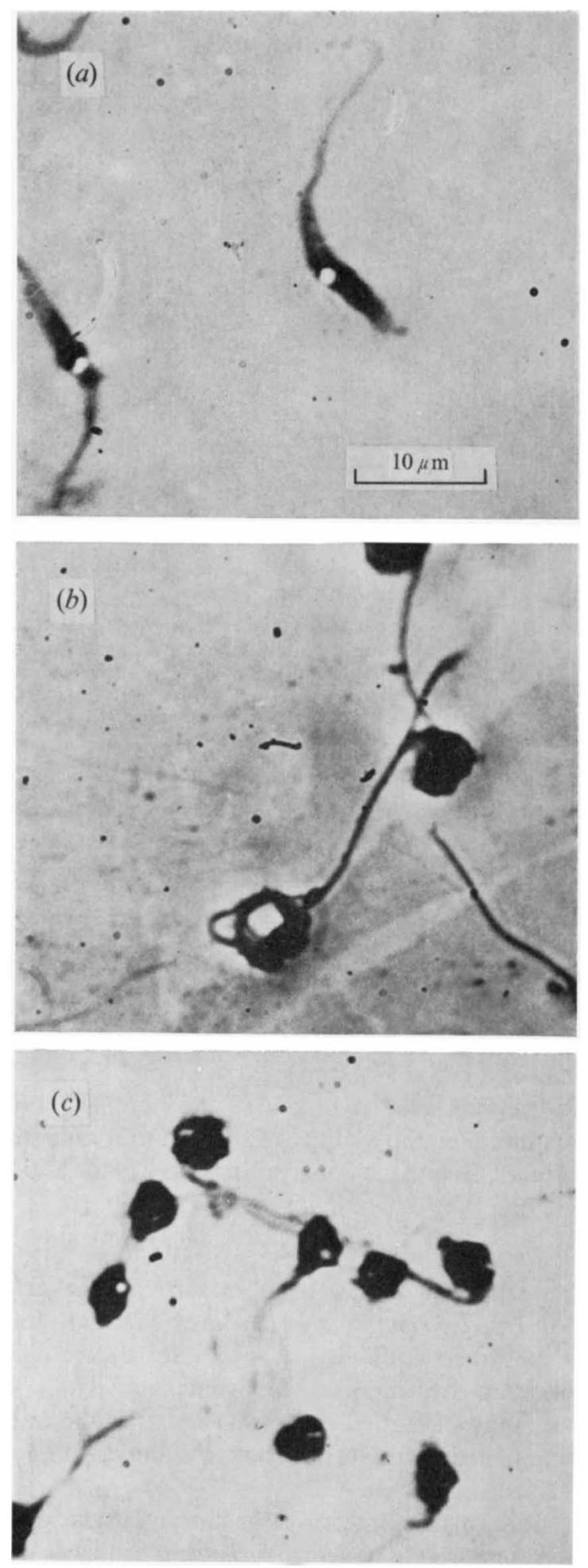

Fig. 2. Epimastigote stage of Trypanosoma cruzi, Md-R. Photographed after $30 \mathrm{~min}$ of incubation. (a) Normal control. (b) Formation of large vacuole in the presence of $380 \mu \mathrm{g}$ of mixed algal fatty acid/ml. (c) Swelling without formation of vacuoles in the presence of $250 \mu \mathrm{g}$ of either decanoic or dodecanoic acid $/ \mathrm{ml}$. 
stage of Trypanosoma cruzi, final readings were taken at $6 \mathrm{~h}$ because the control tubes showed no motility at the next observation time ( $8 \mathrm{~h}$ ). The final readings for the other stages and parasites tested were made at $24 \mathrm{~h}$. A bar graph representing the minimal concentrations of the compounds tested which inhibited the motility of the trypanosomes is given in Fig. I. Octanoic and cis-9-octadecanoic acids were found to be the least inhibitory. Crithidia fasciculata was not inhibited by I $200 \mu \mathrm{g}$ of the crude methanol extract per ml. Stained preparations showed that at given concentrations of the inhibitory compounds morphological changes occurred after $\mathrm{I} h$ exposure. In the presence of $250 \mu \mathrm{g}$ of the algal fatty-acid fraction per $\mathrm{ml}$, or of decanoic acid or dodecanoic acid, the parasites initially rounded up in the manner of a balloon, and lysed after longer contact with these compounds. However, algal fatty acids induced the formation of large vacuoles while none was observed with the known fatty acids (Fig. 2). Octanoic acid at a concentration of $500 \mu \mathrm{g} / \mathrm{ml}$ caused slight roundings of the organisms with no loss of motility. Of the organisms tested, L. tropica was the most sensitive while $C$. fasciculata was the least sensitive to the fatty acids.

\section{DISCUSSION}

Although certain fatty acids are required as growth factors by Trypanosoma cruzi (Citri \& Grossowicz, I954a; Boné \& Parent, I963), our results show that other fatty acids induced membrane instability in this organism. These different effects of fatty acids are probably the results of the fatty-acid growth-factor requirement of these organisms.

It is known that Trypanosoma cruzi is selective with respect to the fatty acids which it will utilize as growth factors (Citri \& Grossowicz, 1954a; Boné \& Parent, 1963). From this, it may be expected that the mechanism for transporting fatty acids across the membranes of $T$. cruzi are relatively specific for cis-9-octadecanoic, octadecanoic, and docosanoic acids. It is then possible that toxic fatty acids such as dodecanoic and decanoic acids will bind to the carrier proteins and penetrate the membrane of the organism without being transported into the cell. This could cause high local concentrations of fatty acids within the membrane resulting in disruption of its structure. The concentration of fatty acid at which disruption occurs would depend on the nature of the acid, the structure of the membrane and the ability of the transport system to recognize various fatty acids. This would account for the variation in the results observed with different fatty acids and organisms and would imply that in $T$. cruzi major differences may exist between the epimastigote and trypomastigote outer membranes.

Crithidia fasciculata which is relatively resistant to the effects of fatty acids does not require exogenous fatty acids for growth (Kidder \& Dutta, 1958) and probably does not possess a fatty-acid transport system with a high degree of specificity.

While it is expected that the higher concentrations of the fatty-acid salts are destroying the organisms by a detergent effect upon their cell membranes (Citri \& Grossowicz, I954b), a mechanism such as that suggested above is necessary to explain the differential effects of the acids upon the organisms and among types of organisms.

That cell permeability was changed was indicated by the formation of large vacuoles within the organism's cytoplasm in the presence of the saponified crude algal extract. Possibly other compounds in the crude extract were responsible for the vacuolation. Dodecanoic and decanoic acids appeared to cause complete disruption of cellular membranes. In contrast, octanoic and cis-9-octadecanoic acids at high concentrations induced little or no morphological changes.

We believe that the differential effects of fatty acids upon these organisms may provide 
a useful approach for designing chemotherapeutic agents which will be effective against members of the Trypanosomatidae.

The results presented here also possess some interesting implications with regard to the development of defined culture media for the growth of trypanosomes. It has been demonstrated in several systems that serum albumin can bind fatty acids and fatty-acid derivatives and thereby relieve inhibitory effects produced by their presence (Wieland, Weiss \& EgerNeufeldt, 1964; Tubbs \& Garland, 1964; Taketa \& Pogell, 1966; Brandes \& Shapiro, 1967). In addition, many serum proteins serve to complex long-chain fatty-acid micelles and thereby protect blood cells from the lytic effects of fatty acids during the transport of non-esterified fatty acids throughout the body. It is quite possible that the addition of serum to culture media will provide some of the fatty acids required by trypanosomes and, at the same time, provide the proteins necessary for the protection of the organisms from the lytic effects of the fatty-acid micelles. As a result, a situation may arise where the addition of the 'wrong' fatty acid to the medium in the absence of serum will lead to lysis of the inoculum, while the addition of serum proteins alone will not produce growth because of a requirement that may be very specific for a particular fatty acid. A similar situation has been considered by Citri \& Grossowicz (1954a, I955). The implications of these results are clear, especially when a mixture of fatty acids such as total serum fatty acids is added to a medium.

This work was supported in part by a grant from the Long Beach Heart Association to S.S.K., and was taken in part from a thesis submitted by L.V.C. in partial fulfilment of the requirements for the degree of Master of Science in Microbiology.

\section{REFERENCES}

Balis, J. (1966). Action of some chemical substances on the survival of Trypanosoma evansi in vitro. III. Fatty acids. Revue d'élevage et de médicine vétérinaire des pays tropical r9, 35I-356.

BarRon, E. J. \& HANAHAN, D. J. (I958). Observations on the silicic acid chromatography of the neutral lipids of rat liver, beef liver, and yeast. Journal of Biological Chemistry 23r, 493-503.

Boné, G. J. \& Parent, G. (1963). Stearic acid, an essential growth factor for Trypanosoma cruzi. Journal of General Microbiology 31, 26I-266.

Brandes, R. \& ShaPIRo, B. (I967). Inhibition of phosphatidic acid phosphatase by palmitoyl-CoA. Biochimica et biophysica acta 137, 202-204.

Citri, N. \& Grossowicz, N. (1954a). The function of blood in the cultivation of Trypanosoma cruzi. Bulletin of the Research Council of Israel 4, 210.

Citri, N. \& Grossowicz, N. (1954b). A liquid medium for the cultivation of Trypanosoma cruzi. Nature, London I73, I100-I IOI.

Citri, N. \& Grossowicz, N. (I955). A partially defined culture medium for Trypanosoma cruzi and some other haemoflagellates. Journal of General Microbiology 13, 273-278.

KIDDER, G. W. \& DutTA, B. N. (1958). The growth and nutrition of Crithidia fasciculata. Journal of General Microbiology r8, 62 I-638.

NiEMAN, C. (1954). Influence of trace amounts of fatty acids on the growth of microorganisms. Bacteriological Reviews 18, 147-168.

TAKetA, K. \& Pogell, B. M. (I966). The effect of palmityl coenzyme A on glucose-6-phosphate dehydrogenase and other enzymes. Journal of Biological Chemistry 241, 720-726.

TubBs, P. K. \& Garland, P. B. (1964). Variations in tissue contents of coenzyme A thio esters and possible metabolic implications. Biochemical Journal 93, 550-557.

WIELAND, O., WeISS, L. \& EgER-NeufeldT, I. (I964). Hemmung der enzymatischen Citronensäuresynthese durch langkettige Acyl-thioester des Coenzyms A. Biochemische Zeitschrift 339, 50I-513. 